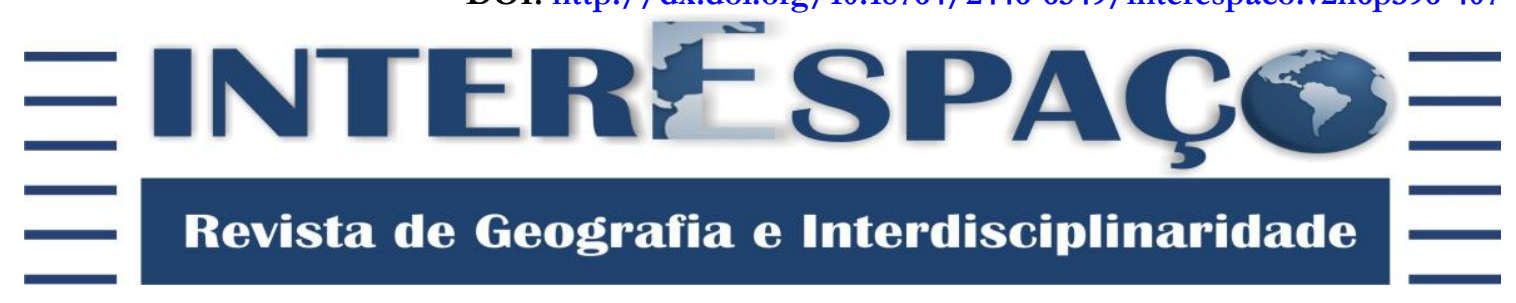

\title{
A NOÇÃO DE ROSTO EM EMMANUEL LEVINAS
}

\author{
Tiago dos Santos Rodrigues \\ Graduado e Mestrando em Filosofia pela Pontifícia Universidade Católica do Rio Grande do Sul - \\ PUCRS. \\ tiagostrodrigues@yahoo.com.br
}

\begin{abstract}
RESUMO
Este artigo pretende apresentar de forma sucinta uma das noções mais importantes do filósofo lituano-francês Emmanuel Levinas: a noção de rosto. Desde a nossa leitura, a noção de rosto é a chave para o entendimento de todo o pensamento de Levinas. O rosto é o modo próprio da alteridade absoluta do outro, não é que a alteridade possua um rosto, mas se é alteridade porque se é rosto. A partir do rosto do outro ser humano o mundo da socialidade e do sentido se abre e com ele também a possibilidade da violência e da injustiça. Mas também é somente por meio dele que a justiça pode ter sentido e realização.
\end{abstract}

Palavras-chave: Rosto; Alteridade; Justiça; Violência.

\section{THE NOTION OF FACE IN EMMANUEL LEVINAS}

\section{ABSTRACT}

This article intend to expose one of the most important notions from the philosopher french-lithuanian Emmanuel Levinas: the notion of face. In our reading, the notion of face is the key to understand Levinas' thought. The face is the own alterity mode, it is not that the alterity possess a face, in fact, the alterity is the face. From the face of another human being, the world of the sociality and of the purport opens, as the very possibility of violence and injustice too. But also, it is just by it that justice can have a sense and realization.

Keywords: Face; Alterity; Justice; Violence.

\section{LA NOCIÓN DEL ROSTRO EM EMMANUEL LEVINAS}

\section{RESUMEN}

Este artículo tiene la intención de presentar brevemente una de las nociones más importantes del filósofo lituano-francés Emmanuel Levinas: la noción del rostro. Desde nuestra lectura, la noción del rostro es la clave para entender todo el pensamiento de Levinas. El rostro es la forma misma de la alteridad absoluta del otro, no es que la alteridad tiene un rostro, pero és alteridad porque és rostro. Apartir del rostro del otro ser humano, el mundo de la sociabilidad y del sentido se abre y con ella la posibilidad de la violencia y la injusticia. Pero es sólo a través de él que la justicia puede tener sentido y realización.

Palabras clave: Rostro; Alteridad; Justicia; Violencia. 


\section{INTRODUÇÃO}

Para Heidegger, o que mais lhe causava espanto na história da filosofia era o esquecimento do ser - esquecimento localizado já desde a época socrática. Por isso ele retorna aos pré-socráticos, os filósofos que para ele não foram surdos à voz do ser. Interessava-lhe o ser e ao ser tudo mais estava subordinado - os entes. O ente possui sentido na medida em que está conforme ao ser. Heidegger, ainda que criticando toda a história da filosofia na censura que lhe faz por ter esquecido o ser, mantêm com ela a primazia da ontologia como filosofia primeira. Levinas, contrariamente ao seu professor, colocará a ênfase no ente. Importará a ele os entes, porque estes são quem sofrem; o ser não sofre, os entes sim. O que lhe causa espanto é o esquecimento do outro. Nesse sentido, o que Levinas oferece é um empirismo radical, é pensar a realidade no seu estado mais cru, ou para usar a expressão de Giorgio Agamben, no seu estado de "vida nua". Para realizar essa crítica à ontologia e à violência, que na sua leitura está a ela associada, Levinas encontrará no rosto uma noção capaz de quebrar as estruturas ontológicas e de fazer frente à violência e à injustiça.

\section{O MESMO NA SUA CASA}

Antes de nos dedicarmos ao rosto do outro, é conveniente darmos algumas palavras sobre a concepção levinasiana de sujeito. O sujeito levinasiano é, em primeiro lugar $^{1}$, um sujeito que goza e que frui do mundo. A primeira relação do sujeito com o mundo não é teorética, não é um "saber de..." Antes que saber de tal e tal coisa, nós saboreamos as coisas - "gozamos de..." Gozamos do ar nos pulmões, do leite materno, de boa sopa e de um abraço, antes de representá-los. Antes de serem ideias na consciência, os elementos do mundo são gozo na sensibilidade. Somos sensíveis ao mundo, na flor da nossa pele, antes que sabedores dele. O sujeito é um sujeito feliz que goza a interioridade do seu mundo e que nele se compraz.

O sujeito como Eu (Moi) é o que se sustém, se possui, o que é senhor de si mesmo, tal como do universo. [...] Assegura o universo como se dele fosse começo. [...] Mas, começo, ele é também acabamento: o fim da história é possessão plena de si por si, presença plena a si (LEVINAS, 2012, p. 211).

\footnotetext{
${ }^{1}$ Esclarecendo: dizemos "em primeiro lugar" a fim de discurso e apresentação do tema, fundamentalmente, o sujeito/subjetividade se apresenta de modo diverso, a qual se verá adiante nessa breve exposição.
} 
Deste modo, o sujeito é na sua crosta, cerrado na sua existência. É totalidade que não conhece alteridade, por isso é um sujeito ateu. Nega outros poderes que não sejam os seus poderes. Tudo ao seu redor é em sua razão, é para a sua satisfação - o mundo é alimento. Como alimento, o mundo é outro diferente do sujeito, mas sujeito à totalização, à alienação, pois é tragável. Aquilo da qual eu me alimento transforma-se em minha energia, em meus poderes, em meu corpo, transforma-se no “eu”. O mundo é para mim e está ao alcance das minhas mãos, mesmo as estrelas na sua distância tornam-se objeto do meu entendimento e do meu prazer.

\section{ROSTO E LINGUAGEM}

Falar da noção de rosto em Emmanuel Levinas é admitir, de partida, que se trata disso mesmo, tão só de uma noção. Trata-se de uma noção porque o rosto é alteridade. A alteridade levinasiana não é uma alteridade numérica, não se é outro de um gênero, não se é mais um em um todo. A comunidade de gênero anula a alteridade (LEVINAS, 2000, p. 173) enquanto que o outro recai na dependência de participar do ser de uma espécie. Gênero e espécie já se referem à ontologia. A alteridade não é alteridade porque ela difira de mim. A diferença supõe o compartilhamento de semelhanças ou uma união originária ${ }^{2}$. Tampouco é uma alteridade lógica: é outro porque não sou eu. A alteridade lógica é função na correlação sujeito-objeto - ela já é reificação, é colocar o outro na comunidade de fronteira, aqui onde eu termino o outro começa; é, portanto, trazer o outro ao meu mundo, mundo onde eu sou senhor. A alteridade do outro, do rosto, é uma alteridade absoluta, não correlativa de qualquer intencionalidade da consciência, não adequada segundo esquemas e estruturas já postas em um mundo. O outro não é outro eu no sentido que seja um outro como eu sou outro: um alter ego. É outro “que” eu. Alteridade que não possui correlativos com o mesmo. É, portanto, Infinito, ideia de infinito em mim. Mas então, como pode ser que o mesmo, que eu sou, alcance de alguma maneira a alteridade infinita que é o outro?

"A diferença absoluta, inconcebível em termos de lógica formal, só se instaura pela linguagem" (LEVINAS, 2000, p. 174). A linguagem é inconcebível em termos de lógica formal porque se ocorresse nela não possuiria sentido, seria, propriamente, uma ilusão ou abstração. Se a alteridade fosse formal, lógica, numérica ou genérica, a alteridade

\footnotetext{
${ }^{2}$ Caso do mito do andrógino que encontramos no Banquete de Platão. Neste, a diferença sexual - homem e mulher - se explica mediante um ser originário que devido ao seu poder foi repartido em dois, o amor, ou se quisermos, a atração entre os gêneros se explicaria devido ao desejo de recuperar a antiga união desfeita.
} 
própria seria uma abstração, pois seria uma parte de um todo na qual eu também compartilharia, eu e o outro seríamos, no fim das contas, um mesmo, e a linguagem nada mais que uma conversa de um ego com seu alter ego. Eu e o outro seríamos uma e mesma substância diferidas, por exemplo, na extensão e no movimento ao estilo espinozista. A requisição à palavra do outro seria requisição da própria palavra - estaríamos cerrados na tautologia. O modelo formal da verdade seria a descoberta, ela já estaria aí à espera do seu desvelamento; tal é o caso da maiêutica socrática que Platão nos legou: a verdade já é um dado presente ainda que não consciente. No entanto,

Um ser que recebe a ideia do Infinito - que recebe, pois não a pode ter de si - é um ser ensinado de uma maneira não maiêutica, um ser cujo existir consiste na incessante recepção do ensino, no incessante transbordamento de si (ou tempo). Pensar é ter a ideia de infinito ou ser ensinado (LEVINAS, 2000, p. 182).

A linguagem só adquire sentido verdadeiro na relação com uma alteridade absoluta. Somente entre alteridades absolutas a saudação logra peso real, isto é, saudamos verdadeiramente outro alguém, somente entre alteridades absolutas o nosso "Oi! Tudo bem?" possui, propriamente, sinceridade e deixa de ser mera ironia esquizofrênica de uma consciência alienada de si. A linguagem é o que atravessa a distância absoluta do "entre nós”. Socorro de seres separados por uma distância instransponível, ela se instaura como sacrum commercium. "A ideia do infinito produz-se na oposição do discurso, na socialidade. A relação com o rosto, com o outro absolutamente outro que eu não poderia conter, com o outro, nesse sentido, infinito, é no entanto minha Ideia, um comércio" (LEVINAS, 2000, p. 176).

O rosto do outro é linguagem e ensinamento, é ideia do infinito em mim que me traz, ou poderíamos dizer, ensina a consciência de exterioridade e, deste modo, a minha própria consciência “O pensamento estabelece uma relação com uma exterioridade não assumida. Como pensante, o homem é aquele para quem o mundo exterior existe" (LEVINAS, 2008, pág. 35). Sendo assim, a relação do mesmo com o outro, do eu com o rosto, pode-se dizer em termos de magistério e discipulado; o outro é mestre, pois inaugura o ensinamento naquilo que ele tem de essencial: a significância da transcendência. $O$ rosto do outro ensina, fala com autoridade uma vez que é autor de sua própria palavra, significa por si-mesmo, não é signo de outro significante: se é sinal, é sinal de si mesmo. E com sua autoridade ensina o primeiro mandamento: Não matarás! "O Olhar é um “Não!” É não ao poder de negá-lo, um não ao não (SUSIN, 1984, p. 211). A interdição ao assassinato é o evento fundante de uma realidade sensata, desse ensinamento dependerá o próprio senso 
de realidade. Se no meu mundo feliz o mundo era para mim, com a entrada do rosto do outro, significando por si mesmo e que por isso é a própria significância, o sentido tem outra formulação, é um-para-o-outro.

\section{ROSTO E TRAUMATISMO}

Contudo, não pensemos que o rosto levinasiano seja representação da forma plástica disso que os seres humanos carregam em suas cabeças. O rosto não é esse conjunto de olhos, nariz, boca e etc. Não é uma somatória de elementos. O rosto é a modalidade própria da alteridade, o modo como o outro se apresenta ausentando-se, a presença do outro, seu rosto, é vestígio (trace), escapa à conceitualização, conceitualização em que as formas plásticas recaem. Não é a minha visão ocular do rosto de outrem que inaugura ou estabelece minha relação com ele. A relação de visão-outro se dá inversamente ao mito de Giges - Giges a todos vê e por ninguém é visto. No choque traumático com o rosto do outro, com essa exterioridade infinita, estranha e que não pede licença, sou visto e não vejo. Sou invadido, perscrutado, perseguido por essa presença incômoda que justamente se recusa a ser presença para mim, que é tão somente um vago vestígio. O rosto é recusa de presentificação, de ser um dado passível à ponderação. Assim, rosto é sensibilidade: o toque, a aproximação, um chorar e um sorrir, a fala e a quietude também saudade. É um modo de ser “não-sendo" porque não se deixa apreender, porque está além (au-delà) do ser e do aparecer, é a ideia de Infinito em mim, pensamento que pensa mais do que pensa, que não contém o que pensa - presença que passa e que fere, ferida que não cicatriza, que permanence não obstante aberta porque foi ferida pelo infinito.

Não se pode, por isso, falar do rosto com propriedade, se fala sempre inapropriadamente em ambas as acepções que essa palavra nos traz, isto é, não se pode falar de modo adequado e, menos ainda, tendo posse. O rosto não se adequa e não se presta à apropriação. O rosto é, em si-mesmo, a in-condição da não-propriedade. É nudez extrema, pura vulnerabilidade na exposição da sua nudez. Nudez porque desprovida de vestuário, de pão, de casa, de sopa. O outro na nudez de seu rosto e do seu olhar é carestia; carece dos verbos auxiliares necessários para gozar de um mundo. No rosto nu, no olhar franco, o outro é sem essência, sem espessura, sem forma, sem ponto de apoio, sem posição, não tem onde repousar a cabeça - não é ser. "A indigência econômica do proletário - também sua condição de explorado - seria a desnudação absoluta do outro 
como outro, a de-formação até ao sem forma, para além da simples mudança de forma" (LEVINAS, 2008, p. 28).

Esta nudez do rosto do outro está além do erotismo e da pornografia que conservam imagem, possuem formas nas quais aparecem e, simultaneamente, escondem-se, portanto, estão mascaradas. "A alteridade total, à qual um ser não se refere à fruição e se apresenta a partir de si, não brilha na forma das coisas pela qual elas se abrem a nós porque, sob a forma, as coisas escondem-se” (LEVINAS, 2000, p. 172). Sendo imagem, entram em um jogo de espelhos, caem no mundo da ontologia, da medida, do intercâmbio, tornam-se produtos, sendo ornados econômica e culturalmente (SUSIN, 1984, p. 213). Ao contrário, a nudez de-formada do rosto é a verdadeira origem do pudor e da vergonha. Vergonha, eis o nascimento da consciência moral! Que é o próprio nascimento da consciência mesma. "O fundamento da cosciência é a justiça" (LEVINAS, 2011, p. 174). No olhar do outro, no face a face com ele, alguém me olha desde abaixo de sua miséria, e acima do meu mundo porque exterior a ele. $\mathrm{O}$ outro é altura que me põe em questão, que questiona os meus poderes. É transcendência que quebra a casca da totalidade, como faixo de luz que rasga a escuridão matutina. $\mathrm{Na}$ vergonha, o sujeito armado com os seus poderes de ser, ter, poder, fazer, é desarmado pelo nada da alteridade do rosto. O aparecimento do rosto é acontecimento traumático, é acontecimento que não provém dos meus cálculos, que não parte do meu querer, que é contra a minha vontade, é apesar de mim (malgré moi), independentemente de meus atributos o sem atributos se introduz inadvertidamente. Assim, voltamos a dizer, é transcendência, pois não é desdobramento da imanência da totalidade. Trata-se, deste modo, de uma violência infligida ao eu. Essa violência é a relação ética; que é o inverso da intencionalidade em que o sujeito lança o seu olhar ao objeto e lhe dá a lei, lhe dá a forma e a norma. No traumatismo ético, o eu é requerido por outrem de modo extremo, sem aviso prévio e sem tempo de pegar fôlego porque, de partida, atrasado ao apelo, porque outrem vem de um passado que nunca me foi presente, de um passado que eu não posso sintetizar que eu não posso representar. No atraso, o eu se encontra em dívida para com o outro, dívida impossível de quitar porque significaria render o outro ao seu mundo, em, propriamente, fazer do outro um mesmo. Nunca me encontro quite com o outro. Assim se expressa a assimetria que há entre o outro e o mesmo, uma desigualdade impossível de nivelar.

\section{ROSTO E HOMICÍDIO}


O rosto é convite ao "tapa na cara", mas, ao mesmo tempo, interdição desse tapa, dessa violência, do assassínio. O rosto diz: "Não matarás". É a impossibilidade ética de fazê-lo, mas não ontológica, pois, certamente tenho o poder de matar a Outrem, como muitos o fazem. Contudo, não tenho desculpas pelo assassínio que perpetro, pois

\begin{abstract}
Só o assassínio aspira à negação total [...] Matar não é dominar mas aniquilar, renunciar em absoluto à compreensão. $\mathrm{O}$ assassínio exerce um poder sobre aquilo que escapa ao poder. Ainda poder, porque o rosto exprime-se no sensível; mas já impotência, porque o rosto rasga o sensível. A alteridade que se eprime no rosto fornece a única "materia" possível à negação total. Só posso querer matar um ente absolutamente independente, aquele que ultrapassa infinitamente os meus poderes e que desse modo não se opõe a isso, mas paralisa o próprio poder de poder. Outrem é o único ser que e posso querer matar (LEVINAS, 2002, p. 211).
\end{abstract}

A pretensão ao assassínio é exclusividade da alteridade do rosto. O que Levinas nos diz aqui é: só posso querer matar a alguém, a quem ofereça resistência à sua morte, somente um alguém, um vivente, pode querer resistir, pode querer não morrer. A "glória" dos matadores se encontra justamente em terem matado a quem resistia ao ato. Esta é a ambiguidade do rosto já mencionada acima: enquanto mandamento de "não matarás", de interdição da aniquilação, é também convite a esse mesmo homicídio, pois oferece a única matéria possível à negação total, quer dizer, é a única coisa onde o assassínio encontra um querer. Por isso o homicídio não encontra des-culpas, não se pode dizer que foi um "sem querer querendo". Assim que a negação do rosto é também a sua prova. Assim que a guerra também atesta a verdade da paz. Porém, ainda que o homicídio seja perpetrado, o assassinato é a derrota do poder de poder matar um rosto, pois, ao matar se traz o rosto ao horizonte do meu mundo, das minhas considerações, reduzo-o à objeto, reifico-o. Mato-o como mato a um animal ou como corto a uma árvore, quer dizer, não alcanço a alteridade do rosto, o rosto como rosto me escapa (LEVINAS, 2010, p. 30), ainda é vestígio.

\title{
ROSTO E SUBSTITUIÇÃO
}

Não se pode se esquivar, se omitir da responsabilidade pela vida do outro. Não sem culpa. Não sem a vergonha - vergonha que atesta a culpa, que dá provas da responsabilidade que, eticamente, é indeclinável e intransferível. Por isso a responsabilidade ao outro não pode ser objeto de negociação, não pode ser barganhada sob o risco de mascarar o rosto do outro, o que é, de fato, negá-lo, e sob o risco de corromper a própria 
unicidade do sujeito nascida no despertar dessa responsabilidade. Uma vez acordada a consciência moral, o outro me persegue, me olha e me acusa. Sou visto, sou visado a todo o instante. Essa perseguição do rosto, do olhar do outro me toma como "refém", não posso escapar, sou tomado, obsidiado pela responsabilidade, obsessão absoluta, extrema que não me deixa em paz, que não traz sossego porque é responsabilidade dirigida a mim e a nenhum outro, responsabilidade que concerne a mim, que me acusa. A mirada do outro me elege. É a mim que ele mira, e não há outro além de mim a que eu posso transferir essa mirada - sou ateu, não há alguém atrás de mim a quem eu possa recorrer ou transferir essa responsabilidade. O outro me concerne, é questão minha; assim que a minha subjetividade, minha ipseidade é despertada. Na condição, que é uma incondição, de refém sou eleito único. Minha unicidade é despertada pelo chamamento de um rosto que se dirige a mim. Não sou massa informe em uma multidão - sou sujeito, isto é: estou sujeitado, sob sujeição, único eleito em uma tarefa na qual ninguém pode me substituir. Sou insubstituível. Ninguém pode tomar o meu lugar no que me compete fazer. No entanto, sou o que a todos substitui. Sou substituição pelo sofrimento do outro, por aquele rosto que carece de pão, vestuário e casa - porque esse sofrimento é sofrimento inútil, porque o sofrimento do outro é sofrimento por nada, é injustiça.

\footnotetext{
Nesta perspectiva, faz-se uma diferença radical entre o sofrimento em outrem na qual é, para mim, imperdoável e me solicita e me chama, e o sofrimento $\mathrm{em}$ mim, minha própria aventura do sofrimento cuja inutilidade constitucional ou congênita pode tomar um sentido, o único de que o sofrimento seja susceptível, tornando-se um sofrimento pelo sofrimento, mesmo inexorável, por alguém (LEVINAS, 2010, p. 121).
}

A solicitação do rosto do outro, que acorda minha subjetividade, que a retira da totalidade imanente satisfeita em si, que a torna única fazendo com que a subjetividade possa enunciar propriamente $\mathrm{Eu}$, me persegue ao extremo de eu me ver como o único respondente de um sofrimento inútil, o sofrimento do outro é inútil porque o outro é separado e, nesse sentido, "santo". O sofrimento em mim, assim somente, ganha sentido; é um sofrer "para que" o outro não sofra. A subjetividade é substituição. O rosto do outro ofendido é causa minha. "A substituição - responsabilidade sem compromisso rememorável, sem começo - aproximação infinita na proximidade de Outrem - não é uma "atitude" que se toma em relação a um ser, próximo no seu rosto." (LEVINAS, 2011, p. 169). Fosse uma atitude, ela começaria em mim, seria uma tomada de posição, seria a minha liberdade atuando, mas ela não tem começo, é anárquica. A responsabilidade da substituição é pura passividade, é a própria in-condição de refém. 
Essa responsabilidade de substituição por ser infinita, e como questão minha, não é reversível porque a igualdade não tem a primeira palavra.

A miséria do rosto do outro ser humano põe em questão meus poderes, meu poder de poder. Põe em questão o meu ser, o meu próprio direito a ser porque nudez do rosto desnuda a minha violência - perante seu rosto sou culpado, eu sou responsável. A vergonha é o brilho da oferta de paz do rosto de outrem, desde a sua altura, desde a sua santidade, iluminando a falsidade da minha "boa consciência", da minha "boa vontade". Na relação reta, direta e sem mediação com o rosto do outro, descubro que a minha subjetividade feliz, satisfeita de si no gozo do mundo e da imanência, é uma subjetividade assassina, que se esqueceu do outro e o deixou morrer. Diante da "boa consciência", a "má consciência" da vergonha não é atividade da subjetividade, é, antes, sofrimento imposto de fora, pura passividade sem intencionalidade (SUSIN, 1984, p. 264). É traumatismo e abertura do infinito.

A abertura traumática do infinito, questionando o meu ser na vergonha, põe em questão o conatus essendi, o esforço que há no ser para permanecer no seu ser, desestabiliza a minha posição no ser. A lei do ser já não conta mais, é preciso um "de outro modo que ser"; não é ser "de" outro modo, não é ser diferente do que sou, porque essas ainda são modalidades do ser, ainda são conatus. É de outro modo "que", diferentemente de ser, não ser mais. É, propriamente, des-interessamento, esvaziar-se, evadir-se do ser. Mas esse des-interessamento, assim como a substituição, não é a partir de mim, ou seja, não é como quando se diz que se faça algo para alguém de modo desinteressado, pois, ainda que possua a sua familiaridade vocabular, este último possui algo de satisfação de si, quer dizer, fico feliz em ter feito o que fiz e/ou me dá prazer em fazer o que faço. Isso tudo ainda é modalidade do ser, pois é modo de posição. O des-interessamento é apesar de mim, é contra a minha vontade e é, anátema contra a lei do ser, sacrifício da minha felicidade (LEVINAS, 2011, p. 115-145).

\section{ROSTO E JUSTIÇA}

No entanto, não existem somente o outro e eu. Existisse somente eu e o outro, o perdão e as desculpas seriam suficientes para apaziguar o mundo. Existisse somente o outro e eu, nos cerraríamos em uma totalidade a dois, na clandestinidade do amor íntimo que se esquece do universo (LEVINAS, 2000, p. 190). O encontro com o rosto é também encontro com a socialidade, com a multiplicidade de alteridades. Encontro não 
somente com uma outra razão, mas com a pluralidade de razões. Com transcendências que a todo o momento traumatizam a totalidade, com rostos que a todo o momento me solicitam. No rosto indigente de outrem brilha também a presença do terceiro - de toda a humanidade sofredora e que "me ordena ordenar". Não é que apareça o outro e depois o terceiro, não. $O$ encontro traumático com a alteridade absoluta é já encontro com a pluralidade de homens e mulheres. Inaugura-se, desse modo, um drama a três ${ }^{3}$, o drama da justiça. Isso porque "tudo o que se passa aqui 'entre nós' diz respeito a toda a gente, o rosto que o observa coloca-se em pleno dia da ordem pública" (LEVINAS, 2000, p. 190). Nesse drama nos enfrentamos não somente com a injustiça e a dor que o outro sofre, mas com a injustiça e a dor que é realizada de outro para com outro. O outro é ofendido, mas também é ofensor. É a hora da justiça, de comparar os incomparáveis, de igualar os inigualáveis, de medir os imensuráveis, é preciso a intencionalidade e o intelecto (LEVINAS, 2011, p. 172), é a hora das instituições e do Estado e a ontologia aqui se justifica - a ciência do ser enquanto ser é função da justiça (LEVINAS, 2011, p. 176). Não é a justiça que deve se adequar a um modelo ontológico, é a ontologia que já vem investida pela justiça. E a política aqui também encontra o seu lugar. Mas não devemos pensar que a justiça, e consequentemente, a política, sejam uma degradação da relação ética. Porque

\footnotetext{
a comtemporaneidade do múltiplo ata-se em torno da dia-cronia de dois: a justiça só se matém como justiça numa sociedade onde não existe distinção entre próximos e longínquos, mas na qual também se conserva a impossibilidade de passar ao lado do mais próximo; na qual a igualdade de todos é sustentada pela minha desigualdade, pelo excedente dos meus deveres sobre os meus direitos (LEVINAS, 2011, p. 173).
}

O rosto do terceiro impede que haja relações de preferência entre mim e o outro, que eu e o outro nos cerremos em uma totalidade cúmplice da desgraça que seja para nós alheia. Mas no entre nós do drama ético, eu permaneço desigual, o eu responde por todos - "somos todos culpados tudo e perante todos, e eu mais que todos", diz Dostoievski na frase que também Levinas assinará. É certo que nos encontramos aqui em uma ambiguidade, que a consciência ética se veja como que negada na tarefa da justiça uma vez que nela se introduz aquilo que, de partida, lhe seria estranho. Mas a própria noção de rosto como vestígio, como não-tematizável, assim o exige. Pois se a justiça pudesse encontrar um termo, se o rosto pudesse encontrar um porto seguro, é porque teria sido

\footnotetext{
${ }^{3}$ Para que fique claro: assim como o rosto não é forma plástica, muito menos o drama a três se refere a uma relação exclusivamente trina, isto é, eu o outro e mais um, mas às relações plurais.
} 
apreendida, seria tema. Ao contrário, o encontro com o rosto do outro, por sua própria condição de infinito, é sempre situação que desestabiliza e que colocará em questão os meus poderes e de qualquer Estado que venha a surgir, mesmo de um Estado que venha a ser solidário. Como se a justiça

\begin{abstract}
se tratasse de uma justiça que se acusa senil e caduca a partir do momento em que as instituições existem para protegê-la; como se, apesar de todos os recursos às doutrinas e às ciências políticas, sociais, econômicas, apesar de todas as referências à razão e às técnicas da Revolução, o homem fosse procurado na Revolução enquanto ela é desordem ou revolução permanente, ruptura dos quadros, supressão das qualidades e, à semelhança da morte, libertando-o de tudo e do todo; como se o outro homem fosse procurado - ou aproximado - numa alteridade em que nenhuma administração jamais poderia atingi-lo (LEVINAS, 2008, p. 27).
\end{abstract}

\title{
CONSIDERAÇÕES FINAIS
}

Sem rosto, o mundo seria anímico, opaco, sem expressão, nada nos diria, nada nos indicaria. Quando olhamos a fachada de uma casa, a frente de um carro ou a capa de um livro, não falamos da cara que eles possuem? O sol não parece que nos ri? A lua como que graceja? Ahab, o velho capitão do Pequod, não tem verdadeiro ódio da baleia Moby Dick a ponto de querer se con-frontar a ela para matá-la? O rosto é significância, e de certo modo, obscenidade. O rosto ofende porque desnuda a todo o momento os simulacros fabricados para esconderem as violências da liberdade assassina de uma razão que se quer absoluta, ou ao menos incontestável. Sejamos livres e felizes: e assim nos tornamos lobos uns dos outros, usurpadores de toda a terra. Queremos ser livres, leves e soltos, queremos viver na leveza do ser, mas essa leveza nos tem sido insustentável. Porém, o rosto é isso que pesa, é carga que nos leva até o chão. Rosto, expressão do infinito e alteridade absoluta. Peso insuportável que abala os alicerces do mundo, do meu mundo e de todos os mundos, gravidade tão densa que nos traz o real, a alteridade do real.

\section{REFERÊNCIAS}

LEVINAS, Emmanuel. Totalidade e infinito. Tradução de José Pinto Ribeiro. Lisboa: Edições 70, 2000.

LEVINAS, Emmanuel. De Deus que vem à ideia. Tradução de Marcelo Fabri, Marcelo Luiz Pelizzoli, Evaldo Antônio Kuiava, Pergentino Stefano Pivatto (coordenador e revisor). Petrópolis: Editora Vozes, 2008. 
LEVINAS, Emmanuel. Entre nós: ensaios sobre a Alteridade. Tradução de Pergentino S. Pivatto. Petrópolis: Editora Vozes, 2010.

LEVINAS. Emmanuel. De outro modo que ser ou para lá da essência. Tradução de José Luis Pérez, Lavínia Leal Pereira. Lisboa: Centro de Filosofia da Universidade de Lisboa, 2011.

LEVINAS, Emmanuel. Deus, a Morte e o Tempo. Tradução de Fernanda Bernardo. Lisboa: Edições 70, 2012.

SUSIN, Luis Carlos. O Homem Messiânico: uma introdução ao pensamento de E. Levinas. Porto Alegre: EST/Vozes, 1984.

Recebido para avaliação em 04/09/2016

Aceito para publicação em 19/01/2017 